\title{
Host Tissue Environment Directs Activities of an Epichloë Endophyte, While It Induces Systemic Hormone and Defense Responses in Its Native Perennial Ryegrass Host
}

\author{
Jan Schmid, ${ }^{1}$ Robert Day, ${ }^{2}$ Ningxin Zhang, ${ }^{1}$ Pierre-Yves Dupont, ${ }^{1}$ Murray P. Cox, ${ }^{1}$ Christopher L. Schardl, ${ }^{3}$ \\ Niki Minards, ${ }^{4}$ Mauro Truglio, ${ }^{1}$ Neil Moore, ${ }^{5}$ Daniel R. Harris, ${ }^{6}$ and Yanfei Zhou ${ }^{1}$ \\ ${ }^{1}$ Institute of Fundamental Sciences, Massey University, Palmerston North 4410, New Zealand; ${ }^{2}$ School of Medical Sciences, \\ University of Otago, Dunedin 9054, New Zealand; ${ }^{3}$ Department of Plant Pathology, University of Kentucky, Lexington 40546- \\ 0312, U.S.A.; ${ }^{4}$ Manawatu Microscopy and Imaging Centre, Palmerston North 4410, New Zealand; ${ }^{5}$ Computer Science \\ Department, University of Kentucky; and ${ }^{6}$ Institute for Pharmaceutical Outcomes \& Policy, University of Kentucky
}

Accepted 25 December 2016.

Increased resilience of pasture grasses mediated by fungal Epichlo $\ddot{e}$ endophytes is crucial to pastoral industries. The underlying mechanisms are only partially understood and likely involve very different activities of the endophyte in different plant tissues and responses of the plant to these. We analyzed the transcriptomes of Epichlö festucae and its host, Lolium perenne, in host tissues of different function and developmental stages. The endophyte contributed approximately $10 \times$ more to the transcriptomes than to the biomass of infected tissues. Proliferating mycelium in growing host tissues highly expressed genes involved in hyphal growth. Nonproliferating mycelium in mature plant tissues, transcriptionally equally active, highly expressed genes involved in synthesizing antiherbivore compounds. Transcripts from the latter accounted for $4 \%$ of fungal transcripts. Endophyte infection systemically but moderately increased transcription of $L$. perenne genes with roles in hormone biosynthesis and perception as well as stress and pathogen resistance while reducing expression of genes involved in photosynthesis. There was a good correlation between transcriptome-based observations and physiological observations. Our data indicate that the fitness-enhancing effects of the endophyte are based both on its biosynthetic activities, predominantly in mature host tissues, and also on systemic alteration of the host's hormonal responses and induction of stress response genes.

All plants are colonized by endophytic microorganisms living within their tissues. Endophytes often benefit their host, and their ubiquitous presence is compelling evidence for their importance in plant life (Hardoim et al. 2015). In spite of their importance, we know little about how plants interact with their endophytes. Such is the case for Epichloë festucae var. lolii (formerly Neotyphodium

Sequence data are available in the GenBank database under accession numbers SRP062084 and GEZW01000000.

Corresponding author: J. Schmid; E-mail: j.schmid@massey.ac.nz

*The $\boldsymbol{e}$-Xtra logo stands for "electronic extra" and indicates that five supplementary figures, four supplementary tables, and 17 supplementary data sets are published online.

(c) (i) () $€$ (C) 2017 The Author(s). This is an open access article distributed under the CC BY-NC-ND 4.0 International license. lolii), the fungal endophyte of perennial ryegrass (Lolium perenne). The increased resilience it confers to its host is crucial to the performance of ryegrass pastures (Johnson et al. 2013). Likewise, because it is exclusively seed-transmitted (Schardl et al. 2007), the endophyte's existence depends on increasing its host's fitness (Fine 1975). E. festucae-mediated fitness enhancements have been documented, namely, increases in the percentage of infected plants over time in partially uninfected $L$. perenne populations (Cunningham et al. 1993; Simpson et al. 2012), increased persistence (Prestidge et al. 1982), pathogen resistance (Tian et al. 2008), protection from herbivores (Johnson et al. 2013), drought tolerance and enhanced growth (Hahn et al. 2008), and better ability to compete with other plant species (Quigley 2000). However, for the endophyte to survive, it only needs to be of net benefit to members of its host species more often than not (Fine 1975) and benefits of endophyte infection are not always observable, depending on plant and endophyte genotypes as well as environmental conditions (Saikkonen et al. 2006, 2016). This, as well as the fact that genetic manipulation of natural Epichlö̈ spp./L. perenne symbioses is extremely challenging (Giri and Praveena 2014; Scott et al. 2012; Zhang et al. 2006), makes it difficult to determine the mechanisms underlying these effects. Only protection against herbivory by endophyte alkaloids is mechanistically well understood (Johnson et al. 2013).

Control of the growth of the Epichloë symbiont and its biosynthetic activities are likely to be an important prerequisite for its benefits to accrue, since supporting the endophyte is a cost to the host. Ideally, just enough endophyte biomass should be present to produce fitness-enhancing effects and as much of the activity of this biomass as possible should be dedicated to producing these effects. We know that expansion of the endophyte mycelium is controlled so as to occur in synchrony with that of the host and only in the newly developing emerging leaf, resulting in well-defined basalapical gradients of low levels (partially determined by plant genotype) of mycelial biomass in above-ground tissues, leaving the root essentially uncolonized (Christensen and Voisey 2007; Herd et al. 1997; Tan et al. 2001). However, we know little about the mechanisms underlying this control, except that they are delicate and important, being easily disrupted, with disruption often associated with catastrophic effects on the symbiosis (Eaton et al. 2010; Scott et al. 2012; Tanaka et al. 2008, 2013; Zhang et al. 2006). We also know that aspects of endophyte-mediated host protection are under some form of control exerted by the host; the concentrations 
in plant tissues of the main known antiherbivore alkaloids peramine, lolitrem, and ergovaline, are determined much less by the concentration of $E$. festucae biomass than by tissue type and the genotype of the host (Spiering et al. 2005). But our understanding of these controls is extremely limited (Chujo and Scott 2014).

It is clear from the above that many of the important interactions between $L$. perenne and its endophyte are tissue-specific. To better understand these interactions, we therefore undertook an analysis of the transcriptomes of endophyte and host in different tissues of infected $L$. perenne plants and of those of matching tissues of uninfected plants. We conducted our analysis in the symbiosis between E. festucae var. lolii Lp19 and the L. perenne clonal line Nui D (Tan et al. 1997; Zhang et al. 2011), arguably the physiologically best-characterized E. festucae var. lolii/L. perenne symbiosis available. This allowed us to search for the transcriptomic basis underlying the previously recorded endophyte growth and metabolic activity patterns (Tan et al. 2001), alkaloid concentration gradients (Spiering et al. 2005), and endophyte impact on plant growth and photosynthesis (Spiering et al. 2006). We also hoped to extend earlier observations on the host response to the Lp19 endophyte (Zhang et al. 2011), i.e., elevated levels of the pathogenesis-related protein PR-10, suggesting that priming (Conrath 2011) of plant defenses by Lp19 infection could be part of its protective effect on the host.

\section{RESULTS}

High contribution of endophyte hyphae to the transcriptomes of all infected tissues.

The Lp19 endophyte is present both in above-ground growing (emerging leaf and stem) and nongrowing tissues (sheaths and blades), with hyphal extension apparently limited to the former (Tan et al. 2001); we confirmed this in the plants used here by assessing fungal biomass distribution (Supplementary Data Set S1). To assess tissue-specific patterns of endophyte gene expression and tissue-specific impacts of endophyte infection on host gene expression, we dissected infected and uninfected ryegrass tillers with two mature leaves into seven tissue fractions (Fig. 1) and analyzed their transcriptomes. Information on growth conditions, sampling, de novo assembly of reads into predicted ORFs, and mapping to these ORFs is provided in the Materials and Methods section below.

Lp19 mycelium contributes between $0.01 \%$, (in the upper emerging leaf), and approximately $0.2 \%$ (in sheaths) of the dry weight of the above-ground tissues (Tan et al. 2001). Interestingly, the endophyte contributed approximately 10 times more to the transcriptome of the tissues it inhabits than to their biomass $(0.20$ to $3.41 \%)$ (Fig. 2A). Remarkably, this was the case both in the emerging leaf, in which the endophyte grows rapidly (Schmid et al. 2000), and in mature plant tissues, in which the endophyte mycelium no longer expands (Tan et al. 2001). Nonextending and extending hyphal networks had comparable transcriptional activity, as indicated by i) a similar distribution of the number of reads mapping to fungal genes and the distribution of fungal DNA across infected tissues (Fig. 2A) and ii) similar ratios of fungal transcripts to fungal protein-coding DNA in all infected tissues (Fig. 2B).

\section{Transcription of genes involved in fungal growth not restricted to hyphal networks that undergo net extension.}

The rapid extension of the endophyte mycelium in the emerging leaf (Schmid et al. 2000) should result in high expression of genes with roles in the generation of new fungal biomass, in particular in the lower emerging leaf, in which most of this extension is thought to occur (Christensen et al 2008). Given that transcriptional activity is undiminished in hyphae in mature plant tissues (sheaths and leaves) in which the mycelium no longer extends (Fig. 2), we expected a major shift of the pattern of gene expression in these hyphae, directing resources away from growth toward other activities. This shift should be apparent in our transcriptome analysis, since fungal mRNAs have half lives of $<2 \mathrm{~h}$ (Geisberg et al. 2014) and extension of the hyphal network in mature plant tissues had ceased several days prior to sampling (Tan et al. 2001).

To characterize the shift, we categorized (as described in Supplementary Data Set S2) functions of the 100 most highly expressed endophyte ORFs in each tissue (Fig. 3) and identified ORFs with tissue-specific expression ( $\geq 4$-fold difference in expression between a tissue and average expression across all tissues or $\geq 2$.4-fold difference between average expression in a pair of tissues and the average expression across all tissues [Fig. 4]). We note that, for all but four of these ORFs (in the "interact $\&$ devel" category, not included in the figure), expression was likely correlated with the rate at which processes occurred in the functional category to which the ORFs had been assigned.

As expected, ORFs associated with the assembly of fungal macromolecular structures accounted for a larger fraction of the 100 most highly expressed fungal ORFs in the lower emerging leaf and the stem (LES) (50\%) than in the mature tissues (14 to 19\%) (Fig. 3). However, no ORFs with functions related to the assembly of fungal macromolecular structures met our criteria for tissue-specific overexpression in the LES (or in the entire emerging leaf) (Fig. 4).

In part, the latter finding might be explicable as a result of a moderate (approximately twofold) increase in fungal biomass over 4 days in mature plant tissues, due to an increase in hyphal thickness after extension of the hyphal network has ceased (Tan et al. 2001).

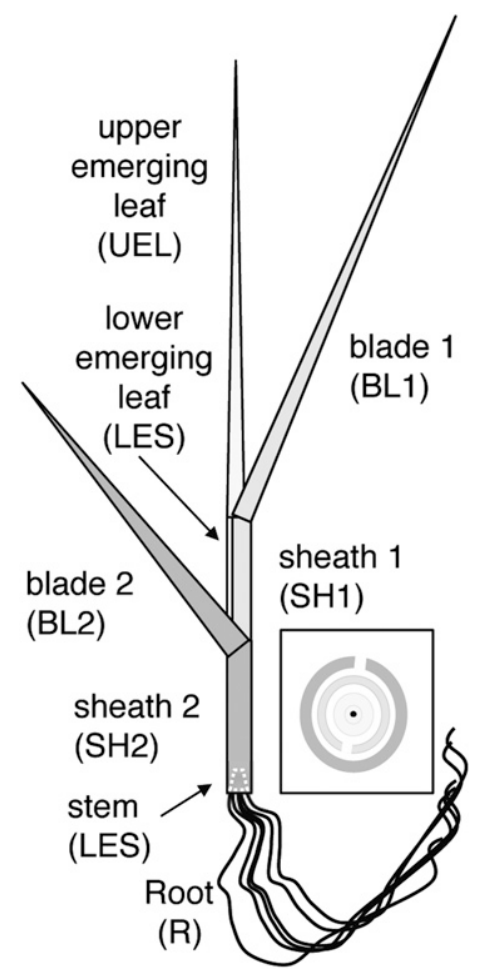

Fig. 1. Two-leaf ryegrass tiller showing the different tissue types analyzed. The tissue types used for analysis and their abbreviations used in text, supplementary tables and other figures are shown. Note that the lower emerging leaf and the stem, the basal meristematic tissue that will give rise to future leaves, were combined (LES). The insert represents a cross section of the lower part of the tiller, with the stem at the center (black circle; dashed lines in side view) surrounded by the emerging leaf (light gray), surrounded by sheath 1 (medium gray) which in turn is surrounded by sheath 2 (dark gray). The roots of tillers in our experiments were longer than shown in the diagram. Typically, they were slightly longer than the above-ground height of the tiller. 
However, the expression of all ORFs in our assembly annotated as having roles exclusive to nuclear DNA replication, a process we expect to be linked to extension of hyphae, also only differed moderately (approximately threefold) between hyphae in the emerging leaf and those in mature plant tissues (Fig. 5). We confirmed that nuclear division was not uncoupled from hyphal extension in mycelia in mature plant tissues; the spacing of nuclei did not differ between hyphae in the lower emerging leaf and in the sheaths (Fig. 6). The simplest explanation of these results is that, in mature plant tissues, parts of the hyphal network break down, requiring continuous replacement growth.

\section{High expression of fungal genes involved} in protecting the grass from herbivory largely restricted to hyphal networks that have ceased net extension.

The transcriptome of older mycelium in mature tissues did reflect a shift from growth toward protective activities that enhance the fitness of the symbiosis. One of the main transcriptomic differences between hyphae in the LES and in other tissues involved genes with roles in protecting the symbiosis from herbivores. No predicted ORFs with such roles were among the 100 most highly expressed ORFs in the LES (Fig. 3), 21 ORFs with such roles met our criteria for tissue-specific reduced expression in the LES and five met our criteria for reduced expression in the entire emerging leaf (Fig. 4). In contrast, predicted ORFs that were likely homologs of genes known (or likely) to be involved in the synthesis of compounds protecting the symbiosis from
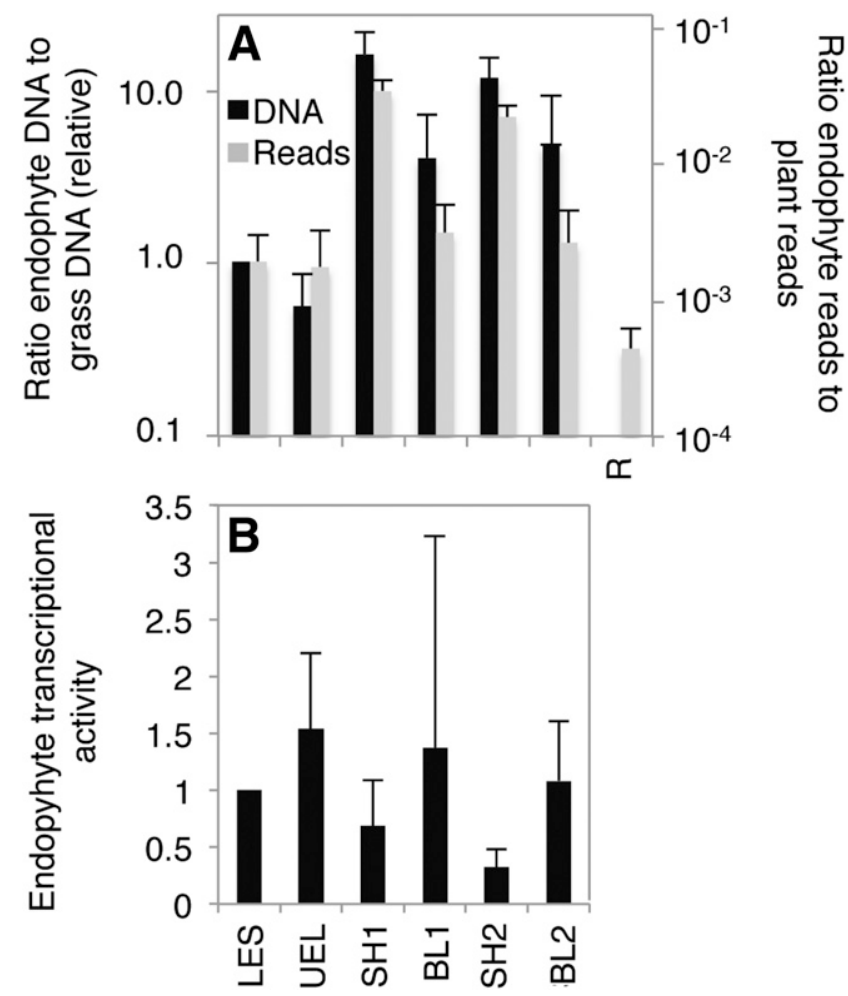

Fig. 2. Endophyte contribution to nuclear DNA and transcriptome of infected tissues and transcriptional activity of the endophyte. A, Black bars indicate the ratio of endophyte DNA to grass DNA, as determined by quantitative polymerase chain reaction (qPCR), with lower emerging leaf plus stem (LES) as a calibrator ( $\mathrm{qPCR}$ crossing points indicate a ratio in LES of approximately 1:20,000 [Zhou et al. 2014]). Gray bars indicate the ratio between reads mapping to endophyte open reading frames (ORFs) and reads mapping to grass ORFs. Error bars represent standard deviations. B, Endophyte transcriptional activity. This was determined as the ratio of $E$. festucae tefB RNA to $E$. festucae tefB ORF DNA (determined by qPCR), divided by the ratio of reads mapping to $E$. festucae tefB to all reads mapping to $E$. festucae ORFs. Values shown are relative to those in the lower emerging leaf. herbivores and biotic stressors (Supplementary Data Sets S3 and S4) accounted for 10 to $16 \%$ of the most highly expressed ORFs in non-LES tissues (Fig. 3). Their expression was fairly uniform across all mature tissues (Fig. 4). The vast majority of these protection-conferring ORFs had predicted roles in the biosynthesis of lolitrem and ergot alkaloids. Two homologs of the Epichlö̈ $m c f$-like gene (Ambrose et al. 2014), encoding the Mcf-like insect toxin protein, met our criteria for reduced expression in the emerging leaf.

A large number of ORFs in the "interact \& devel" category, highly expressed in BL2 (Fig. 4), almost exclusively reflected high expression of predicted ORFs that are likely homologs of an E. festucae ABC transporter-encoding gene. Similarities between these predicted ORFs suggest that the number of Lp19 genes in the "interact \& devel" category highly expressed in BL2 may be considerably smaller $(<6)$ than the figure suggests.

The increased expression of lolitrem and ergot alkaloid genes in mature plant tissues was not unexpected, given that levels of these alkaloids are also highest in mature tissues of Lp19/Nui D symbioses (Spiering et al. 2005). The genes involved in the synthesis of ergot and lolitrem are well characterized (Schardl et al. 2013), allowing us to identify a total of 30 likely homologs in our de novo-assembled ORFs. Seventeen lolitrem biosynthesis gene homologs and 13 ergot biosynthesis gene homologs all followed the pattern described above and that of alkaloid distribution, being expressed 8.7- to 32.7-fold (average 25.5-fold) and 1.3- to 9.7-fold (average 6.7-fold) higher, respectively, in mature tissues than in the LES (Fig. 7A and B). Within each pathway, expression of all genes changed in a coordinated fashion. The expression of individual ORFs relative to the level of expression of all ORFs of the same pathway differed little between tissues, especially between different mature tissues (Fig. 7A and B). Also consistent with the alkaloid profiles of the Lp19/Nui D symbioses (Spiering et al. 2005), transcripts from lolitrem biosynthesis genes constituted a very substantial portion of fungal transcripts in mature tissues ( 3 to $5 \%$ ), whereas ergot alkaloid genes were expressed at much lower levels, i.e., 0.09 to $0.15 \%$ of fungal transcripts in mature tissues were derived from these genes (Fig. 7A and B).

Two methyltransferases, ClrD and EzhB, inhibit lolitrem and ergot biosynthesis by silencing the genes involved (Chujo and Scott 2014). We tested if the $c l r D$ and $e z h B$ expression patterns

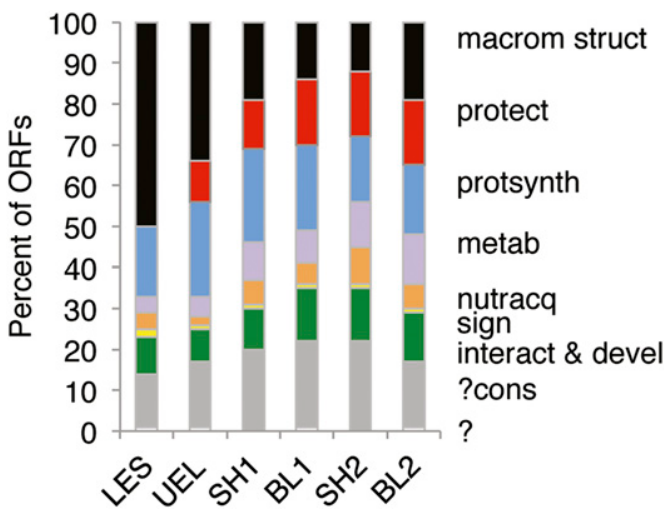

Fig. 3. Distribution of functions among the 100 most highly expressed Epichloë open reading frames (ORFs) in different plant tissues. ORFs were assigned to the following predicted function categories: synthesis of macromolecular structures (macrom struct, black), synthesis of metabolites known to protect or potentially capable of protecting from herbivory (protect, red), protein synthesis (protsynth, blue), other metabolic reactions (metab, purple), nutrient acquisition (nutracq, orange), regulatory functions including receptor kinases (sign, yellow), interaction with the host and developmental regulation (interact \& devel, green), encoding conserved proteins with unknown functions (? cons, light gray), and no good BLAST hits (?, white). 
implicated them in the reduced expression of lolitrem and ergot biosynthesis genes in the LES. Their expression was higher in the LES than in mature tissues, albeit only by $15 \%$, (Supplementary Fig. S1).

A predicted ORF homologous to the single gene required for the synthesis of the insect deterrent peramine (perA) had an expression pattern different from that of lolitrem and ergot alkaloid biosynthesis genes. Similar to peramine concentration (Spiering et al. 2005), its expression was more uniform and highest in the emerging leaf and sheath 1 , where its transcripts accounted for 0.03 to $0.04 \%$ of fungal transcripts (Fig. 7C). In contrast, the expression pattern and levels of the insect-toxinencoding mcf-like resembled those of ergot alkaloid biosynthesis genes (Fig. 7D).

Its inferred function and an expression pattern similar to that of alkaloid genes suggest a possible involvement of one additional endophyte gene in protecting the symbiosis, namely an ORF with significant similarity to ORFs encoding fungal phosphonopyruvate decarboxylases (PPDs). PPDs carry out the second step in the biosynthesis of phosphonoacetaldehyde, a precursor of compounds with C-P bonds (Metcalf and van der Donk 2009; Peck and van der Donk 2013). The ORF was among the 100 most highly expressed fungal ORFs in all tissues except the LES (capturing approximately $1 \%$ of all reads mapping to endophyte ORFs in the former and $0.004 \%$ in the latter). Judging by our de novo assembly, $L$. perenne lacks a PPD-encoding gene, but it highly expressed a gene encoding the enzyme phosphonopyruvate mutase (PepM), carrying out the first step of phosphonoacetaldehyde biosynthesis (Peck and van der Donk 2013); the endophyte apparently has no PepMencoding gene (Supplementary Data Set S5). This suggests that, jointly, endophyte and host may synthesize C-P compounds; since many $\mathrm{C}-\mathrm{P}$ compounds are antimicrobials or herbicides (Metcalf and van der Donk 2009; Peck and van der Donk 2013), this could provide the symbiosis with added protection from pathogens or plant competitors, or both.

\section{Predominant expression of Epichlo $\ddot{e}$ genes encoding putative small secreted proteins (SSPs) in the LES.}

We found, in our assembly, 28 likely homologs of putative SSP-encoding E. festucae genes (Eaton et al. 2015; Supplementary Data Set S6). SSPs can function as tissue-specific effectors, mediating colonization of host tissue (Plett and Martin 2015). Suggestive of such roles, expression of 13 of these SSPencoding genes was higher in the LES than in any other tissue, approximately $2 \times$ more often than expected by chance $(P<$ 0.002; binominal test), and two of these ORFs met our criteria for significant overexpression in the LES (Fig. 4, "interact \& devel" category). One of these was among the 100 most highly expressed ORFs in the LES.
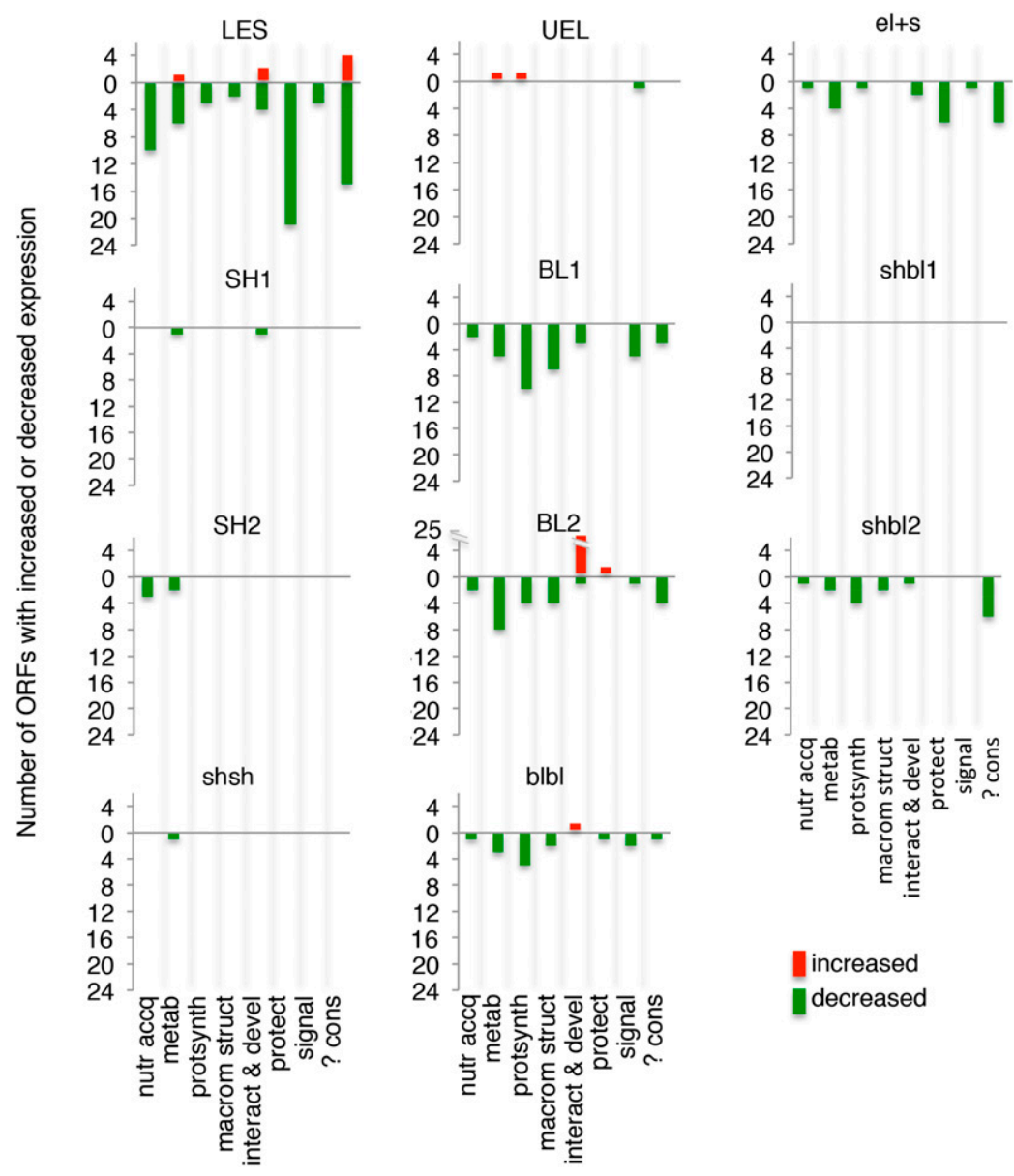

Fig. 4. Grass tissue-specific expression differences for E. festucae open reading frames (ORFs). ORFs were identified that captured a $\geq 4$-fold higher or lower fraction of all reads that mapped to endophyte ORFs in a tissue than the average across all tissues or $\geq 2.4$-fold more or less in a pair of tissues. ORFs were then categorized according to predicted function categories, and numbers of ORFs in each category were plotted for each tissue type or pair of tissue types. For pairs of tissues, the abbreviations are: upper emerging leaf (UEL) plus stem (LES), el+s; sheath 1 plus blade 1, shbl1; sheath 2 plus blade 2, shbl2; both sheaths, shsh; mature blades one and two, blbl. The length of the upward-pointing bars above the $x$ axis indicates the number of ORFs that captured a higher fraction of reads, the length of the downward- pointing bars below the $x$ axis indicates the number of ORFs in each category that captured a lower fraction. 
Systemic plant defense-, hormonal signaling-, and photosynthesis-related transcriptional responses to endophyte infection.

To estimate the magnitude of the impact of endophyte infection on the transcriptome of each of the seven plant tissues, we determined the differential between the number of ORFs whose expression was either consistently increased or consistently decreased in an endophyte-infected tissue in three biological replicates and the expected number of ORFs that would behave in this fashion in the absence of an endophyte effect (detailed below in the Materials and Methods section). The analysis indicated that, on average, $\geq 6,000$ plant ORFs were affected in each tissue (Supplementary Fig. S2), including the essentially uncolonized (Christensen and Voisey 2007) root.

We next identified, in each tissue, ORFs for which the software DEGseq (Wang et al. 2010) indicated significant changes of expression. For 32,710 ORFs, i.e., 34\% of all 96,709 de novo-assembled grass ORFs, endophyte infection significantly affected expression in one or more tissues. The numbers of ORFs affected in each tissue were similar to the above estimates (average 11,777 ORFS, 6 to 19\% of all ORFs) (Fig. 8).

The extent of the transcriptomic response of the host tissues to endophyte infection was thus not determined by endophyte biomass concentration. Neither did the vastly different activities of the endophyte in different tissues (this paper; Tan et al. 2001) trigger a matching differential in responses. Only a small fraction of significant responses to endophyte infection were specific to a single tissue (Fig. 8). More often than not, expression of a given ORF was either significantly increased in several tissues or decreased in several tissues (Fig. 8; Supplementary Fig. S3). Of 1,663 predicted plant ORFs that responded significantly to endophyte infection in all tissues, $1,272(76 \%)$ either showed increased expression in all tissues or decreased expression in all tissues. Likewise, when we identified, in each tissue, the $10 \mathrm{ORF}$ for which statistically significant effects of endophyte infection were most pronounced, $92 \%$ of these ORFs consistently increased or decreased expression in multiple (usually three or more) tissues (Supplementary Data Set S7).

Thus, the endophyte elicited a systemic response. To elucidate its nature, we selected, from among the universally affected ORFs, 318 for which endophyte infection altered expression $\geq 2$-fold in all tissues and attempted to determine their probable functions. This was possible for 289 ORFs, and these functions could be assigned to a small number of categories (Supplementary Data Sets S8 and S9). Since a given ORF often had properties that associated it with several of these categories, the results of this analysis are presented as a matrix (Fig. 9).

One main component of the systemic impact of endophyte infection was the increased expression of genes contributing to the protection of the plant from biotic and abiotic stresses (Ahmad et al. 2011; Donà et al. 2013; Kovalchuk et al. 2003; Martin et al. 2003; Pandey and Somssich 2009; Treutter 2005), such as genes involved in benzoxazinoid and flavonoid biosynthesis, encoding disease-resistance proteins, WRKY transcription factors, and transposase (Fig. 9, "protect" category). However, consistent with reverse transcription polymerase chain reaction (PCR) assay data (Zhang et al. 2011), no $P R$ genes (van Loon et al. 2006) showed a systemic $\geq 2$-fold response (Supplementary Fig. S4). The second main component of the systemic response to endophyte infection was an increase in the expression of genes involved in the synthesis, transport of, and responsiveness to plant hormones, including salicylic acid, jasmonate, gibberellin, ethylene, abscisic acid, cytokinin, and auxin. (category "hormonsyntrans" and "hormresp"; we note that we observed a similar distribution of functions, i.e., predominantly defense and hormone synthesis and transportrelated functions, for ORFs that were among the 10 most strongly significantly endophyte-affected in one or several tissues). Figure 9 also illustrates that endophyte infection impacts on a multitude of regulatory mechanisms of its host. Indeed ORFs encoding proteins involved in regulatory processes are the largest category seen in Figure 9. While the actual impact of the majority of these changes is difficult to predict, annotations of proteins with significant homology to the ones encoded by these ORFs suggest that many may play a role in altering growth and development of endophyte-infected $L$. perenne.

To fully capture its most important effects, we also assessed the impact of endophyte infection on the 100 most highly expressed grass ORFs (based on the average expression level across all seven tissue types in infected and uninfected plants [Supplementary Data Set S10]). Expression of all of these ORFs was significantly affected by endophyte infection in most tissues, usually slightly reduced; 505 of 700 possible comparisons indicated reduced expression, by $35 \% \pm 48 \%$, and 86 indicated increased expression, by $21 \%$ $\pm 18 \%$. Of the 100 ORFs, 74 were chloroplast-associated, and the average of 442 significant effects across all of these was a reduction of expression by $27 \%$. The reduced expression of chloroplast-associated genes may be partially caused by reduced chloroplast numbers in endophyteinfected plants (Fig. 10). We assessed chloroplast numbers in bundle sheath cells. In infected plants, chloroplast numbers were reduced by $17 \%(9.5 \pm 1.5$ versus $11.4 \pm 1.6$ per cross section, $P<1.3 \times 10^{-6} ; t$ test; averages in each of three infected plant replicates were lower than three uninfected plant replicate averages). Bundle sheath cell size was also reduced by $38 \%$ (area of largest cross sections, $P<2.1 \times$ $10^{-10} ; t$ test).

To confirm that our analyses had captured the main endophyte effects, we identified Gene Ontology (GO) terms overrepresented among genes affected by endophyte infection in an automated GO annotation of $L$. perenne ORFs produced by Blast2GO (Conesa and Götz 2008). While Blast2GO yielded GO terms for only $15 \%$ of the grass ORFs, the $143 \mathrm{GO}$ terms overrepresented among ORFs responding to infection were broadly consistent with the results of the above analyses (Supplementary Data Set S11).

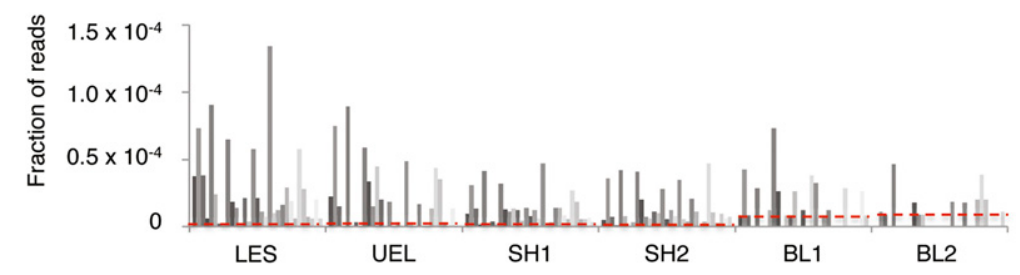

Fig. 5. Expression of endophyte open reading frames (ORFs) involved in nuclear DNA replication in different tissues. Shown are the fractions of all reads mapping to all endophyte ORFs that were captured by each of 31 Epichlö̈ ORFs with predicted roles in nuclear DNA replication (Supplementary Data Set S15). Red lines show the lowest level of transcript detectable in each tissue type; i.e., for ORFs to which no reads mapped in a tissue, their true level could approximate the level indicated by the red line. 
Observed responses of the $L$. perenne transcriptome to $E$. festucae endophytes can differ considerably when different symbioses are assessed.

Dupont et al. (2015) also recently investigated the transcriptomic response of $L$. perenne to E. festucae, using a mixture of basal above-ground tissues, a different $E$. festucae strain not native to $L$. perenne, different $L$. perenne genotypes, and different growth conditions. Contrary to observations reported here and earlier (Zhang et al. 2011), they saw a reduction in the expression of defense-related genes. This prompted us to investigate how much observed host responses in two different experimental models of $L$. perenne/E. festucae symbioses can differ, transcriptome-wide, taking advantage of the fact that both studies used overlapping sets of gene models. There was little correlation between the two data sets in terms of the effects of E. festucae infection on individual ORFs. The comparison also indicated that, in our experiments, fewer than half as many plant ORFs were affected by endophyte infection than in the experimental system used by Dupont and coworkers (2015) (Supplementary Data Set 12).

\section{DISCUSSION}

Our data add several pivotal facets to our understanding of the E. festucae-perennial ryegrass symbiosis. One key finding is the large contribution by the endophyte to the transcriptome of the symbiosis, approximately 10 times greater than its contribution to the biomass of infected tissues. Given that transcript numbers are a reasonable reflection of trancriptional activity (Geisberg et al. 2014) and the correlation between genomewide transcription rate and metabolic rate (Desvergne et al. 2006), this suggests that the metabolic rate per unit weight of the endophyte is also higher, by a similar degree, than that of the host. The magnitude of this differential approximately matches expectations under Kleiber's law that describes the relationship between body mass and metabolic rate (DeLong et al. 2010; Niklas and Kutschera 2015) for free-living organisms. This is consistent with the assumption (Tan et al. 2001) that the plant does not control the endophyte by restricting its access to resources. It also indicates that the resource cost to the host may be considerably higher than its contribution to the biomass of the symbiosis suggests.

A key observation regarding endophyte growth is that, in mature plant tissues, the expression of genes involved in biomass synthesis and nuclear DNA replication decreases much less than the current model of in planta fungal growth predicts. According to the model, endophyte growth stops once the surrounding host tissue has matured (Christensen et al. 2002, 2008; Tan et al. 2001). However, this assumption is almost entirely based on measurements of fungal biomass concentration in different tissues (Christensen et al. 2002; Tan et al. 2001), since fungal growth in planta can only be directly observed with extreme difficulty for brief periods of time (Christensen et al. 2008). Strictly speaking, all we know is that no net extension of mycelium occurs in mature host tissues. Perhaps, similar to events in arbuscular mycorrhiza (AM) (Alexander et al. 1988), some hyphae die over time in mature plant tissues, balanced by regrowth. The fungal transcriptome does not suggest elevated levels of apoptosis in mature plant tissues (Supplementary Data Set S13). Perhaps, as is the case in AM (Breuillin-Sessoms et al. 2015), the plant may bring about the death of these hyphae.

Even if the mycelium in mature plant tissues undergoes some regrowth, its undiminished transcriptional activity (Fig. 2B) is largely directed toward other processes. Both the endophyte transcriptome in these tissues and their alkaloid content (Spiering et al. 2005) suggest that, as we hypothesized earlier (Tan et al. 2001), this older mycelium plays a dominant role in synthesizing fungal compounds that enhance the fitness of the symbiosis. This applies, foremost, to lolitrem and ergot biosynthesis genes. It is difficult to ascertain directly how well expression of these genes correlates with the rates of the multitude of reactions catalyzed by the enzymes they encode (Schardl et al. 2013). However, three observations support the notion that expression levels and the rates at which these pathways operate are correlated. First, concentration differences between tissues of the protective alkaloids lolitrem and ergovaline each matched differences in mRNA levels of the genes involved in their synthesis (Spiering et al. 2005). Second, the ratio of lolitrem to ergovaline concentrations (Spiering et al. 2005) matched the ratio of concentrations of mRNAs encoded by the genes involved in their synthesis. Third, within both the lolitrem and the ergot multistep pathways, individual member ORFs showed similar changes in expression among tissues (Fig. 7A and B), indicating that transcription of all ORFs in each pathway was coordinated. The simplest explanation of these findings is that the differences in alkaloid levels among tissues are the result of operation of the entire pathways in all tissues but at different rates, with pathway rates mirroring the levels of expression of the genes involved, i.e., that transcriptional regulation is a major determinant of the level of alkaloids produced. An inverse correlation between levels of mRNAs of lolitrem and ergot biosynthesis genes and levels of $\operatorname{clr} D$ and $e z h B$ mRNAs implicate the lolitrem and ergot biosynthesis-inhibiting methyltransferases encoded by the latter (Chujo and Scott 2014) in the plant tissue-specific repression of alkaloid pathway genes. The $\operatorname{clr} D$ and $e z h B$ expression differentials between tissues are smaller than those of the alkaloid genes, suggesting that additional factors are involved, for instance, other parts of the fungal methylation machinery (Du et al. 2015). In addition, plant signals are likely to play a role, as suggested by large differences in ergot/lolitrem ratios in the same tissue type when different ryegrass genotypes are infected with Lp19 (Spiering et al. 2005). Similar regulatory mechanisms might guide the expression of two other genes, also predominantly and highly expressed by hyphae in mature plant tissues, i.e., the insect toxin-encoding (Ambrose et al. 2014) $m c f$-like gene and a putative PPDencoding gene. The latter could be involved in the synthesis, jointly with the host, of C-P compounds (Metcalf and van der
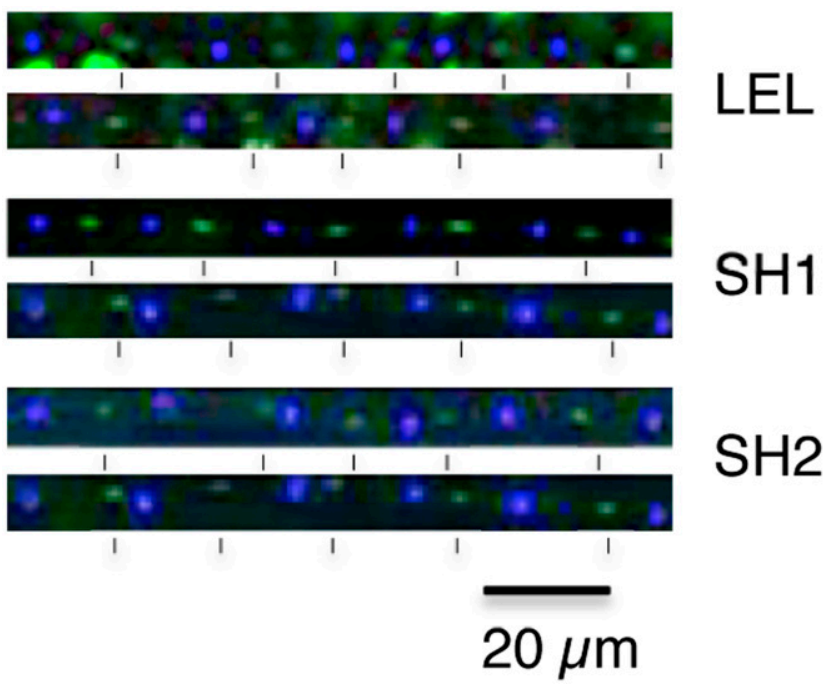

Fig. 6. Spacing of nuclei and septa in hyphae in the lower emerging leaf (LEL), sheath 1 (SH1), and sheath 2 (SH2). Nuclei (green) were stained with propidium iodide and septa (blue) with wheat germ agglutinin-AlexaFluor 488 and were visualized by confocal microscopy. Two representative hyphae from each tissue type are shown. Vertical lines below each hypha mark the position of nuclei. 
Donk 2009; Peck and van der Donk 2013), which could function as additional means of endophyte-mediated protection from pathogens and assist in competing with other plants.

Likely contributing to the evolution of the spatial expression patterns of genes involved in host protection is the need for Epichlö̈ spp. to both colonize and protect the host, within the resources at its disposal. This, perhaps, explains why the expression of the perA gene is highest in the LES, and peramine levels in the LES are comparable to those in older tissues (Spiering et al. 2005). Only one enzymatic reaction, carried out by the peramine synthetase encoded by perA, is required to synthesize peramine from primary metabolites (Tanaka et al. 2005). Peramine biosynthesis is, thus, intrinsically more "affordable" than that of lolitrem, ergot, and the protein insect toxin, affordable enough to allow rapidly growing hyphae to provide the emerging leaf with some herbivore protection.

We have previously argued that establishing a functional L. perennelE. festucae symbiosis might involve signaling mechanisms similar to those in AM (Zhang et al. 2011).
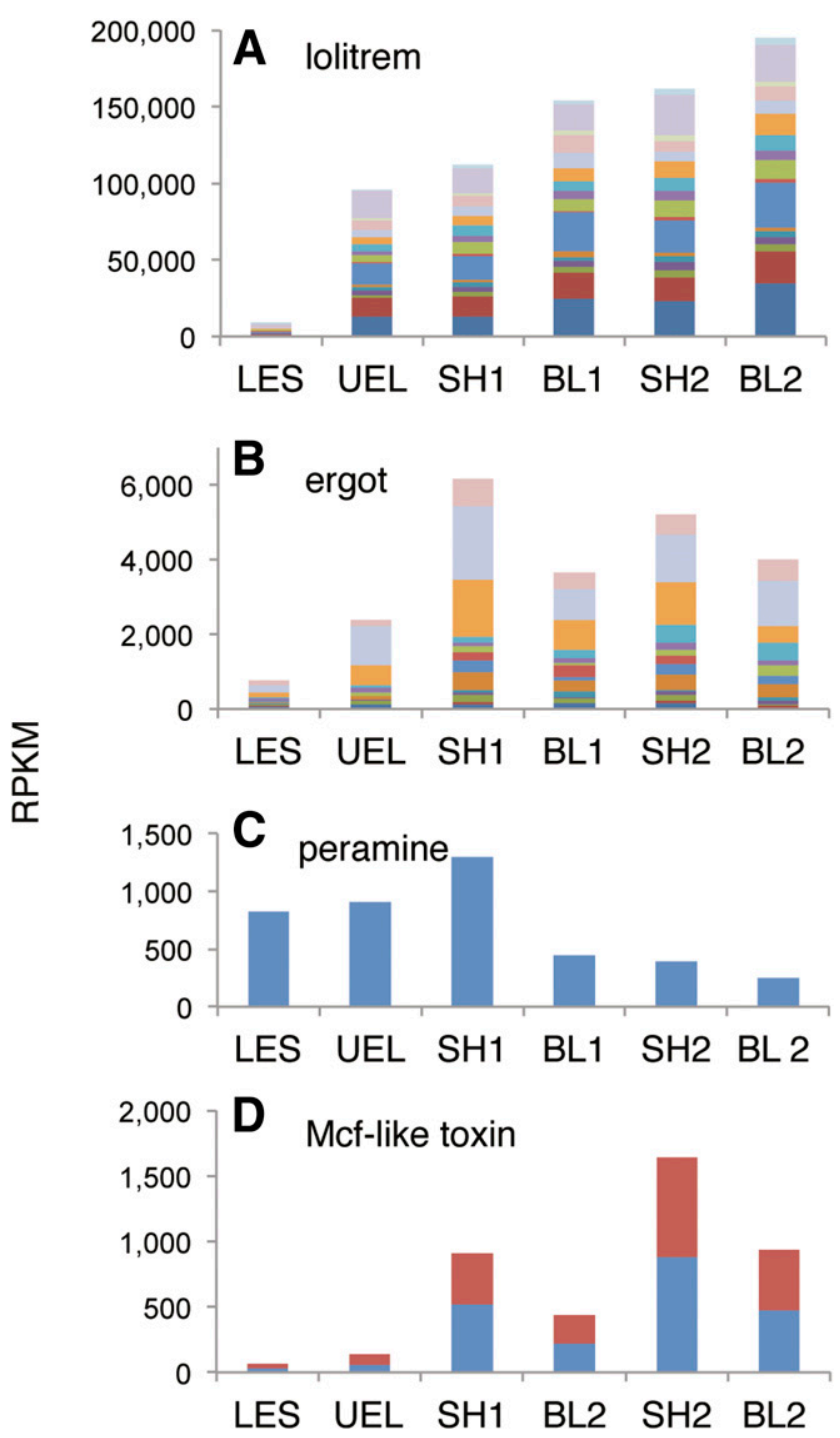

Fig. 7. Expression levels of Epichlö̈ alkaloid pathway and $m c f$-like insect toxin genes in different plant tissues. Expression levels of genes encoding enzymes in the $\mathbf{A}$, lolitrem pathway, $\mathbf{B}$, ergot pathway, $\mathbf{C}$, peramine pathway, and D, Mcf-like toxin-encoding genes. Expression levels in RPKM (reads per kilobase of transcript per million reads mapped to Epichlö̈ open reading frames [ORFs]) for predicted Epichlö ORFs that are likely homologs of these genes are shown (synthesis of lolitrem, 17 ORFs; ergot, 14 ORFs; peramine, one ORF; Mcf-like toxin; two ORFs).
Supporting this hypothesis, we found parallels in the expression of putative SSP-encoding genes. AM fungi temporarily express genes that encode SSPs during colonization, which function as effectors, interacting with host transcription factors (Plett and Martin 2012, 2015). Likewise many SSP-encoding Epichlö̈ genes are predominantly expressed in the LES, suggesting that their temporary expression could be involved in colonization of the emerging leaf.

In another parallel to mycorrhiza (Song et al. 2015) Lp19 infection leads to a moderate increase of expression of genes involved in a multitude of biotic and abiotic stress defenses. Many of these responses are systemic, and their occurrence in the essentially uncolonized (Christensen and Voisey 2007) root adds to a growing list of Epichloë effects on host roots (Dinkins et al. 2017; Malinowski et al. 1999; Vázquez-de-Aldana et al. 2013). It appears that, as in mycorrhiza (Jung et al. 2012; Song et al. 2015), the endophyte primes these defenses, allowing the plant to react more quickly and efficiently to biotic and abiotic stressors (Conrath 2011). Our transcriptomics data only demonstrate that endophyte infection causes increased expression of genes with roles in meeting these challenges, reducing the amount of new transcripts that need to be synthesized when they occur. However, the impact of E. festucae on the actual response of ryegrass to stress also supports the hypothesis that it primes host defenses; E. festucae infection reduces the susceptibility of ryegrass to fungal pathogens and increases the levels of superoxide dismutase and peroxidase produced in response to these

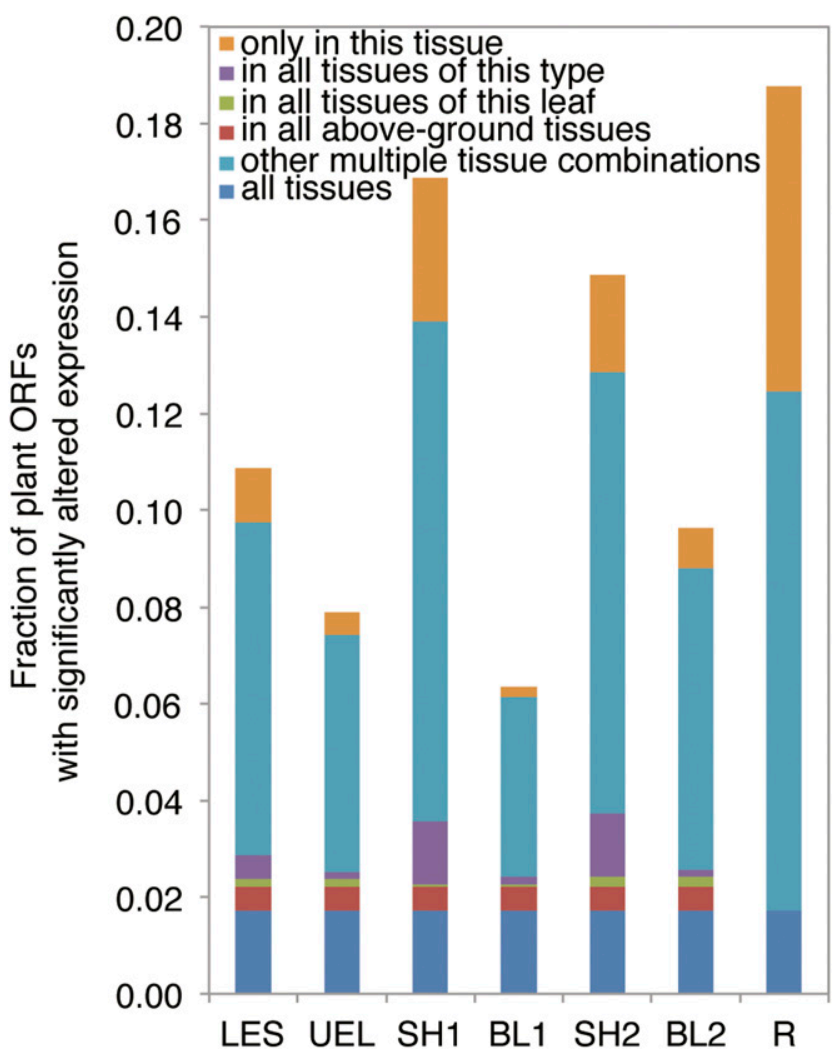

Fig. 8. Impact of endophyte infection on plant gene expression in individua tissues. For each tissue type, the fraction of all 96,709 Trinity-predicted L. perenne open reading frames (ORFs) for which expression was significantly altered in endophyte-infected plants is shown. Different colors indicate the fraction of ORFs significantly altered in i) that tissue type only, ii) all mature and immature tissues of the same type (LEL, SH1 plus SH2, or UEL, BL1 plus BL2), iii) ORFs affected in this tissue and other tissues all belonging to the same leaf (LES plus UEL, SH1 plus BL1, or SH2 plus BL2), iv) other multiple tissue combinations, including this tissue, v) ORFs affected in all above-ground tissues, and (vi) ORFs affected in all tissues. 
pathogens (Tian et al. 2008; Wiewióra et al. 2015), as well as increasing PR-10 protein levels in the absence of a pathogen challenge (Zhang et al. 2011). E. festucae infection can also ameliorate the effects of drought stress (Hahn et al. 2008) and is associated with a faster rise in proline (Hahn et al. 2008) and superoxide dismutase levels upon drought stress (Briggs et al. 2013).

Increased expression of genes involved in synthesis, transport, and perception of the plant hormones salicylic acid, jasmonate, gibberellin, ethylene, abscisic acid, cytokinin, and auxin in Epichlö̈-infected plants may be part of priming (Jung et al. 2012) and not only because hormones are directly involved in defense (De Vleesschauwer et al. 2014). Mounting a defense requires resources, and these need to be diverted from photosynthesis and growth (Reitz et al. 2015; Scharte et al. 2005). This could underlie the reduced photosynthesis of Lp19infected plants (Spiering et al. 2006), their reduced bundle sheath cell size, and chloroplast numbers. Changes in plant hormone signaling can bring about these changes (Reitz et al. 2015). Increased hormone levels and diversion of resources toward defense could also underpin the endophyte effect on tillering and leaf extension (Spiering et al. 2006), but the connections between hormone and growth effects of endophyte infection will be complex. As the number of tillers in grass tufts increases, Lp19 endophyte infection first increases then decreases rates of tillering and leaf extension (Spiering et al. 2006); likewise, the hormones to whose synthesis, transport, and perception the endophyteinduced plant genes contribute have opposing effects on tillering and leaf extension (Ljung et al. 2001; McSteen 2009). Changes in other regulatory mechanisms, as indicated by the high number of ORFs with predicted regulatory roles (Fig. 9), are also likely to play a role in altering plant growth and development.

The host's transcriptomic response we observed is consistent with physiological data (Spiering et al. 2006), with an earlier observation that Lp19 induces a mild pathogen response in the Nui D host (Zhang et al. 2011), and observations indicating priming of stress responses in other $L$. perenne genotypes infected with native endophytes (Briggs et al. 2013; Hahn et al. 2008; Johnson et al. 2003; Tian et al. 2008; Wiewióra et al. 2015). However, it bears little resemblance to the response of the $L$. perenne transcriptome to a non-native $E$. festucae strain (much more pronounced and including suppression of defenses [Dupont et al. 2015]) and to the small number of effects, none systemic, induced in L. arundinaceum by its native endophyte E. coenophiala (Dinkins et al. 2017). Interestingly, these very different plant transcriptome responses are associated with comparable outcomes, in that endophyte infection has no immediately obvious negative effects on the host and neither are there ultrastructural signs of a plant defense against the endophyte. How the different responses affect fitness of the infected

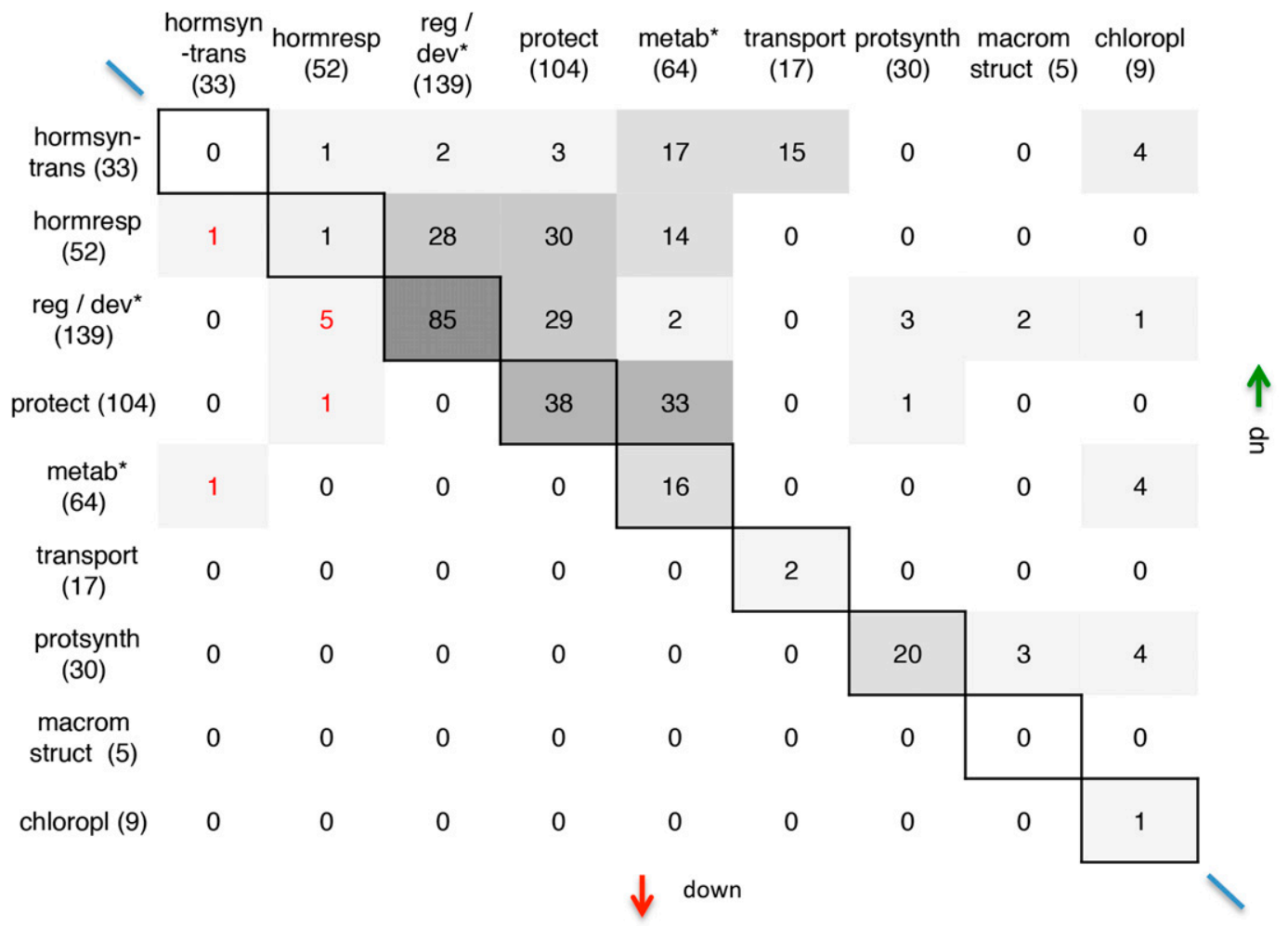

Fig. 9. Predicted systemic effects of endophyte infection on the grass, inferred from ubiquitous grass transcriptome changes. The figure is based on 289 Trinitypredicted Lolium perenne open reading frames (ORFs) whose expression was significantly altered in all tissues of endophyte-infected plants by a factor of two or more and for which a likely function could be inferred. Predicted functions of these ORFs are categorized into nine categories, namely, "hormsyntrans", hormone synthesis and transport; "hormresp", response to hormones"; "reg/dev" regulation and plant development; "protect", defense against biotic and abiotic stresses; "metab", metabolic reactions (excluding those covered in other categories); "transport"; "protsynth", protein synthesis; "macrom struct", synthesis of macromolecular structures; "chloropl", located in chloroplast. Numbers in brackets behind category names indicate the number of ORFs associated with each category. Because the same ORF was often associated with several of these categories, the data are presented as a matrix showing the number of ORFs assigned to all pairwise combinations of functional categories. Increasingly dark shading categorizes the number of ORFs assigned to each pair of categories ( $>0,>10,>20,>30$, and $>40$ ). The upper triangle matrix shows the numbers of ORFs in pairs of categories for which expression data indicated an increase in the rate of processes in question (increased expression or reduced expression of an inhibitor of such processes). For two categories (reg/dev and metab, marked by an asterisk) directionalities of effects could not be inferred and this was also the case for some ORFs associated with other categories. Numbers of ORFs associated with such effects are also shown in the upper triangle. The lower triangle matrix shows the number of ORFs assigned to pairs of categories for which the expression data suggest a reduction in the rate of the processes in question. Numbers in bordered cells indicate numbers of ORFs exclusively mapping to one category, in all cases indicating likely increases in the rate of processes in that category as deduced from the expression changes of the ORFs associated with that category. 
plants is unknown. They could all increase fitness, at least at the host population level. Responses observable in individual plant clones (this study; Dinkins et al. 2017) or small groups of clones (Dupont et al. 2015) could be part of a spectrum of responses simultaneously present in the sexually reproducing and, thus, genotypically diverse infected grass populations, with different responses being advantageous under different conditions.

The mild defense response that Lp19 elicits doubtlessly is of some cost to the Nui D plants, but it does not significantly decrease host fitness during vegetative growth, even in the absence of stressors against which it could protect. We have propagated the Lp19/Nui D symbiosis for over ten years and have only very rarely encountered endophyte-free tillers, expected to arise (Christensen 1995) and increase in frequency if loss of the endophyte were selectively advantageous. This suggests that the type of response we observed has a net benefit and that the hypothesis that Epichlö̈-induced priming of L. perenne's defenses underpins the increased resilience of populations of these plants to a broad variety of stresses warrants further investigation.

\section{MATERIALS AND METHODS}

Biological material, growth conditions, and harvesting of plant material.

All plants were from clonal line Nui D of L. perenne cv. Nui (Tan et al. 1997). One Nui D plant had been infected with E. festucae var. lolii Lp19 (Zhang et al. 2011) eight years prior to the experiments described here. We grew plants, as described earlier (Zhang et al. 2011), under controlled conditions (approximately $700 \mu \mathrm{mol}$ photons $\mathrm{m}^{-2} \mathrm{~s}^{-1}$ at canopy height for $12 \mathrm{~h}$ per day, $15^{\circ} \mathrm{C}$, in 1.4-liter pots) on three separate occasions, providing three biological replicates. We harvested tillers with two mature leaves from exponentially tillering plants and dissected them into seven different tissue sections (Fig. 1). For RNA sequencing, above-ground tissue sections were harvested from five to seven tillers from at least three different pots and were pooled. Root material was harvested from at least two different pots, was rinsed with tap water to remove soil, and was pooled. Pooled samples were submerged in liquid nitrogen. An additional two to three tillers were harvested at the same time and were stored in the same fashion to be used in quantitative (q)PCR assays. In addition three to four tillers were set aside for microscopy.

\section{Determination of the ratio of fungal to plant DNA.}

The ratio of fungal to plant DNA was determined, as described previously (Zhou et al. 2014), by comparing, via qPCR, copy numbers of the Epichlö var. lolii $\operatorname{ltm} G$ gene and the

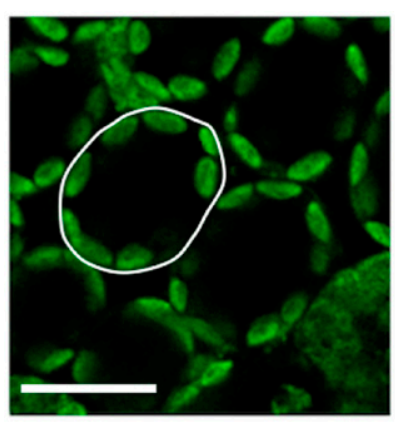

uninfected

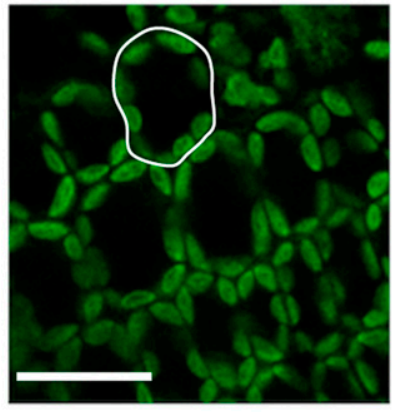

infected
Fig. 10. Bundle sheath cells with chloroplasts, visualized by autofluorescence. The largest optical slices of cells, viewed from the direction of the blade surface, are shown. The outline of one cell in each image is marked with a white line. Scale bars represent $25 \mu \mathrm{m}$.
L. perenne Tubl gene in total DNA extracted from tissue sections, with the DNeasy plant mini kit (Qiagen), according to manufacturer's instructions.

\section{RNA extraction.}

Plant material was ground with a pestle and mortar, both precooled with liquid nitrogen. RNA was isolated with TRI reagent (Molecular Research Center, Inc.), following the manufacturer's instructions. The quantity and purity of the RNA were estimated by the ratio of absorbances at 260 and $280 \mathrm{~nm}$ and were verified by $2 \%$ sodium dodecyl sulfateagarose gel electrophoresis. The integrity of the RNA was assessed with an Agilent Technologies 2100 bioanalyzer (the RNA integrity number of all preparations was $>7$ ).

\section{Transcriptome sequencing and read mapping.}

RNA was used by New Zealand Genomics Ltd. to make TruSeq libraries for Illumina paired-end 100-bp sequencing. To capture a sufficient number of endophyte transcripts, infected tissues were sequenced in greater depth (Supplementary Table S1).

We mapped reads (Bowtie 2; default settings [Langmead and Salzberg 2012]) against predicted ORFs de novo-assembled from reads from the first biological repeat (Dupont et al. 2015), including 9,567 E. festucae ORFs and 96,708 L. perenne ORFs. Endophyte and grass have multiple genes encoding virtually the same protein or truncated versions of the protein (Schardl et al. 2004; Zhang et al. 2011). We therefore mapped to all of these ORFs, even though, not infrequently, different de novoassembled ORFs were highly similar or even identical to each other. We explored mapping only to representatives of groups of highly similar ORFs but concluded that, while this would not significantly alter our conclusions, it was likely to be less informative (data not shown). See Supplementary Data Set 14 for additional information on mapping.

\section{Determination of $E$. festucae transcript to protein-coding DNA ratios.}

Plant tissue (20 to $30 \mathrm{mg}$, from two tillers) was ground as described above. The ground tissue was spiked with $200 \mathrm{ng}$ of Dothistroma septosporum (NZE10) DNA and $700 \mathrm{ng}$ of D. septosporum total RNA, prepared from liquid cultures with DNeasy and RNeasy Qiagen kits. Half of the spiked powder was used to extract DNA, the other half to extract RNA (using the same Qiagen kits). The RNA preparation (10 $\mu \mathrm{g})$ (concentration determined by absorption at $260 \mathrm{~nm}$ ) was incubated at $37^{\circ} \mathrm{C}$ for $20 \mathrm{~min}$ with DNase I (1 U/ $\mu$ g; Invitrogen), followed by thermal inactivation of the enzyme $\left(65^{\circ} \mathrm{C}\right.$ for $\left.10 \mathrm{~min}\right)$. The treated RNA was column-purified (RNeasy plant mini kit). cDNA was synthesized from $1 \mu \mathrm{g}$ of RNA with Transcriptor reverse transcription (Roche).

We amplified tefB cDNA and genomic DNA-derived amplicons and D. septosporum Tubl cDNA and Verl genomic DNA (Supplementary Table S2 provides accession numbers of the genes, primers, and amplification conditions) in a Lightcycler 480 with SsoFast EvaGreen Supermix (Bio-Rad) in a set of 24 reactions (four amplifications each for seven tissue types of the material to be assessed; LES, upper emerging leaf, sheaths 1 and 2 , blades 1 and 2, and roots), to determine the concentration of all four templates in the starting material used for extraction, relative to their concentration in the LES sample. From this, for each tissue, the ratio tefB $\mathrm{cDNA}$ to tefB genomic DNA was calculated and divided by the ratio Tubl cDNA to Verl genomic DNA to correct for differences in DNA and RNA recovery. This provided an extraction efficiency-corrected estimate of the ratio tefB RNA to $t e f B$ genomic DNA, relative to the ratio in the LES. This corrected tefB $\mathrm{cDNA} /$ tef $B$ ratio was divided by the fractions of all reads in mRNA samples extracted from the same tissue type 
material at the same time and mapping to a de novo assemblypredicted ORF (m.22227), which has $99.98 \%$ identity with the gene model EfM3.021210 in the E. festucae genome, the tefB gene of E. festucae (Schardl et al. 2013). The resulting ratio obtained for each tissue was divided by the ratio calculated for the LES.

\section{Assessing tissue-specific expression of endophyte genes.}

DESeq (Anders and Huber 2010) was used to generate, for each endophyte ORF in each endophyte-containing tissue, normalized read counts toward endophyte ORFs, averaged across the three biological replicates. By dividing these by the sum of all normalized counts toward endophyte ORFs in a tissue, an average fraction was generated. Using these, we identified ORFs with $\geq 4$-fold difference in expression between a tissue and average expression across all tissues or $\geq 2.4$ difference between average expression in a pair of tissues and the average expression across all tissues; these cut-offs assured that such ORFs had two or more times higher or lower expression in a single tissue or in a pair of tissues than in all remaining tissues.

For tissues with low endophyte content, the minimum possible average fraction of all reads that could map to an Epichloë ORF was approximately $5 \times 10^{-6}$. Thus, uniform expression of an ORF below this level in all tissues could falsely suggest its elevated expression in tissues with high endophyte content, since some reads would map to it in these tissues but no reads would map to it in low-endophyte content tissues. In addition stochastic variation in very small numbers of reads in lowendophyte content tissue could falsely generate the appearance of large expression differences. Thus, we included in these comparisons only ORFs for which either the average fraction of reads mapping to the ORF across these low-endophyte content tissues was ten times higher (i.e., $5 \times 10^{-5}$ ) or the fraction of reads mapping to one or more tissues with elevated expression was 20 times higher than this threshold $\left(1 \times 10^{-4}\right)$.

For assessing if SSP-encoding ORFs were expressed predominantly in the LES more often than expected per chance, we used 28/138 as a conservative ratio under the null hypothesis, with 28 being the number of such ORFs in our assembly and 138 being the number of times expression could have been observable in six infected tissues $(6 \times 28=168)$ minus the number of times (30) in which no expression was detectable in low-endophyte content tissues UEL, BL1, and BL2.

\section{Assessing the impact of endophyte infection on the host transcriptome.}

To estimate the number of plant ORFs affected by endophyte infection, we first determined, for each tissue type from each biological replicate, how many $L$. perenne ORFs captured a higher percentage of reads in a tissue from endophyte-infected plants than in the same tissue from uninfected plants (upregulated ORFs). Likewise, we determined how many ORFs captured fewer reads if the tissue was from endophyte-infected plants (downregulated ORFs). From this, we calculated, for each tissue type, the number of ORFs that, by chance, would appear to be consistently affected by the presence of the endophyte in all three replicates even if there was no consistent effect, as

$$
E\left(\text { ORF }_{\text {change }}\right)=N_{\text {ORFs }}\left(\prod_{i}^{i=3} \frac{N_{i}^{u}}{N_{\text {ORFs }}}+\prod_{i}^{i=3} \frac{N_{i}^{d}}{N_{\text {ORFs }}}\right)
$$

where $N_{\text {ORFs }}$ is the total number of ORFs, $N_{i}^{u}$ is the number of upregulated ORFs, and $N_{i}^{d}$ is the number of downregulated ORFs across the $i$ biological replicates.

We subtracted this from the number of ORFs that did, indeed, show a consistent endophyte effect in all three replicates. The result is a conservative estimate of the true number of ORFs that was consistently affected by the presence of the endophyte.
The software DEGseq v. 1.16.0 (Wang et al. 2010) was used to identify significant (false discovery rate $q<0.05$ ) differences in expression of individual ORFs among tissues of the same type from infected and uninfected plants.

\section{Visualization of Epichlö̈ nuclei and septa by confocal microscopy.}

This was carried out following methods described by Berry (2016) and Becker et al. (2016). In brief, tissues were fixed in $95 \%$ ethanol. Following immersion in $10 \%$ potassium hydroxide for $3 \mathrm{~h}$, tissues were placed in phosphate-buffered saline containing $0.02 \%$ propidium iodide (Life Technologies) and $0.001 \%$ WGA-AF488 (wheat germ agglutinin-AlexaFluor 488; Molecular Probes). Nuclei and septa were visualized with a Leica SP5 DM6000B confocal laser-scanning microscope (excitation $466 \mathrm{~nm}$, emission 498 to $551 \mathrm{~nm}$ for nuclei; excitation $561 \mathrm{~nm}$, emission 571 to $737 \mathrm{~nm}$ for septa).

\section{Microscopy of bundle sheath cells.}

The basal regions of outer blades from two-leaf tillers were cut parallel to the blade surface to reveal the vascular bundles. Focusing downward from the direction of the blade surface with the confocal laser-scanning microscope, the area of optical sections at the greatest diameter of each of 136 bundle sheath cells from three biological replicates was measured (ImageJ software, version $1.47 \mathrm{v}$, National Institutes of Health; LOCI Bio-Formats Importer plugin). In 77 optical sections from three biological replicates, chloroplasts were visualized (autofluorescence; $633 \mathrm{~nm}$ excitation, 643 to $789 \mathrm{~nm}$ emission, HCX PL FLUOTAR $40 \times$ dry objective, numerical aperture 0.75 ) and counted.

\section{ACKNOWLEDGMENTS}

We are grateful for the assistance of S. Zhang, Y. Wang, and $\mathrm{R}$. Bradshaw in the development and implementation of the RNA/DNA ratio assay. We thank D. Wheeler for assistance with some of the bioinformatics analyses. M. Spiering, C. Young, and P. Dijkwel made valuable comments and suggestions regarding the manuscript. The cost of sequencing by New Zealand Genomics Ltd. was subsidized by the New Zealand Ministry for Business Innovation and Employment. AgResearch Grasslands, the Bioprotection Centre, and the Marsden Fund provided funding towards this work.

\section{LITERATURE CITED}

Ahmad, S., Veyrat, N., Gordon-Weeks, R., Zhang, Y., Martin, J., Smart, L., Glauser, G., Erb, M., Flors, V., Frey, M., and Ton, J. 2011. Benzoxazinoid metabolites regulate innate immunity against aphids and fungi in maize. Plant Physiol. 157:317-327.

Alexander, T., Meier, R., Toth, R., and Weber, H. C. 1988. Dynamics of arbuscule development and degeneration in mycorrhizas of Triticum aestivum L. and Avena sativa L. with reference to Zea mays L. New Phytol. 110:363-370.

Ambrose, K. V., Koppenhöfer, A. M., and Belanger, F. C. 2014. Horizontal gene transfer of a bacterial insect toxin gene into the Epichlö fungal symbionts of grasses. Sci. Rep. 4:5562.

Anders, S., and Huber, W. 2010. Differential expression analysis for sequence count data. Genome Biol. 11:R106.

Becker, M., Becker, Y., Green, K., and Scott, B. 2016. The endophytic symbiont Epichlö̈festucae establishes an epiphyllous net on the surface of Lolium perenne leaves by development of an expressorium, an appressorium-like leaf exit structure. New Phytol. 211:240-254.

Berry, D. (2016). Characterisation of novel secondary metabolism genes in plant-endophytic Epichloë fungi. Ph.D. thesis. Massey University, Palmerston North, New Zealand.

Breuillin-Sessoms, F., Floss, D. S., Gomez, S. K., Pumplin, N., Ding, Y., Levesque-Tremblay, V., Noar, R. D., Daniels, D. A., Bravo, A., Eaglesham, J. B., Benedito, V. A., Udvardi, M. K., and Harrison, M. J. 2015. Suppression of arbuscule degeneration in Medicago truncatula phosphate transporter4 mutants is dependent on the ammonium transporter 2 family protein AMT2;3. Plant Cell 27:1352-1366. 
Briggs, L., Crush, J., Ouyang, L., and Sprosen, J. 2013. Neotyphodium endophyte strain and superoxide dismutase activity in perennial ryegrass plants under water deficit. Acta Physiol. Plant. 35:1513-1520.

Christensen, M. J. 1995. Variation in the ability of Acremonium endophytes of Lolium perenne, Festuca arundinacea and F. pratensis to form compatible associations in the three grasses. Mycol. Res. 99: 466-470.

Christensen, M. J., Bennett, R. J., Ansari, H. A., Koga, H., Johnson, R. D., Bryan, G. T., Simpson, W. R., Koolaard, J. P., Nickless, E. M., and Voisey, C. R. 2008. Epichlö endophytes grow by intercalary hyphal extension in elongating grass leaves. Fungal Genet. Biol. 45:84-93.

Christensen, M. J., Bennett, R. J., and Schmid, J. 2002. Growth of Epichloë/Neotyphodium and p-endophytes in leaves of Lolium and Festuca grasses. Mycol. Res. 106:93-106.

Christensen, M. J., and Voisey, C. R. 2007. The biology of the endophyte/grass partnership. Pages 123-133 in: Proceedings of the 6th International Symposium on Fungal Endophytes of Grasses, A. J. Popay and E. R. Thom, eds. New Zealand Grassland Association, Palmerston North, New Zealand.

Chujo, T., and Scott, B. 2014. Histone H3K9 and H3K27 methylation regulates fungal alkaloid biosynthesis in a fungal endophyte-plant symbiosis. Mol. Microbiol. 92:413-434.

Conesa, A., and Götz, S. 2008. Blast2GO: A comprehensive suite for functional analysis in plant genomics. Int. J. Plant Genomics 2008:619832.

Conrath, U. 2011. Molecular aspects of defence priming. Trends Plant Sci. 16:524-531.

Cunningham, P. J., Foot, J. Z., and Reed, K. F. M. 1993. Acremonium/grass interactions perennial ryegrass (Lolium perenne) endophyte (Acremonium lolii) relationships: The Australian experience. Agric. Ecosyst. Environ. 44:157-168.

De Vleesschauwer, D., Xu, J., and Höfte, M. 2014. Making sense of hormone-mediated defense networking: From rice to Arabidopsis. Front. Plant Sci. 5:611.

DeLong, J. P., Okie, J. G., Moses, M. E., Sibly, R. M., and Brown, J. H. 2010. Shifts in metabolic scaling, production, and efficiency across major evolutionary transitions of life. Proc. Natl. Acad. Sci. U.S.A. 107: 12941-12945.

Desvergne, B., Michalik, L., and Wahli, W. 2006. Transcriptional regulation of metabolism. Physiol. Rev. 86:465-514.

Dinkins, R. D., Nagabhyru, P., Graham, M. A., Boykin, D., and Schardl, C. L. 2017. Transcriptome response of Lolium arundinaceum to its fungal endophyte Epichlö̈ coenophiala. New Phytol. 213:324-337.

Donà, M., Macovei, A., Faè, M., Carbonera, D., and Balestrazzi, A. 2013. Plant hormone signaling and modulation of DNA repair under stressful conditions. Plant Cell Rep. 32:1043-1052.

Du, J., Johnson, L. M., Jacobsen, S. E., and Patel, D. J. 2015. DNA methylation pathways and their crosstalk with histone methylation. Nat. Rev. Mol. Cell Biol. 16:519-532.

Dupont, P.-Y., Eaton, C. J., Wargent, J. J., Fechtner, S., Solomon, P., Schmid, J., Day, R. C., Scott, B., and Cox, M. P. 2015. Fungal endophyte infection of ryegrass reprograms host metabolism and alters development. New Phytol. 208:1227-1240.

Eaton, C. J., Cox, M. P., Ambrose, B., Becker, M., Hesse, U., Schardl, C. L., and Scott, B. 2010. Disruption of signaling in a fungal-grass symbiosis leads to pathogenesis. Plant Physiol. 153:1780-1794.

Eaton, C. J., Dupont, P. Y., Solomon, P., Clayton, W., Scott, B., and Cox, M. P. 2015. A core gene set describes the molecular basis of mutualism and antagonism in Epichlö̈ spp. Mol. Plant-Microbe Interact 28:218-231.

Fine, P. E. 1975. Vectors and vertical transmission: An epidemiologic perspective. Ann. N. Y. Acad. Sci. 266:173-194.

Geisberg, J. V., Moqtaderi, Z., Fan, X., Ozsolak, F., and Struhl, K. 2014. Global analysis of mRNA isoform half-lives reveals stabilizing and destabilizing elements in yeast. Cell 156:812-824.

Giri, C. C., and Praveena, M. 2014. In vitro regeneration, somatic hybridization and genetic transformation studies: An appraisal on biotechnological interventions in grasses. Plant Cell Tissue Organ Cult. 120:843-860.

Hahn, H., McManus, M. T., Warnstorff, K., Monahan, B. J., Young, C. A., Davies, E., Tapper, B. A., and Scott, B. 2008. Neotyphodium fungal endophytes confer physiological protection to perennial ryegrass (Lolium perenne L.) subjected to a water deficit. Environ. Exp. Bot. 63: 183-199.

Hardoim, P. R., van Overbeek, L. S., Berg, G., Pirttilä, A. M., Compant, S., Campisano, A., Döring, M., and Sessitsch, A. 2015. The hidden world within plants: Ecological and evolutionary considerations for defining functioning of microbial endophytes. Microbiol. Mol. Biol. Rev. 79: 293-320.
Herd, S., Christensen, M. J., Saunders, K., Scott, D. B., and Schmid, J. 1997. Quantitative assessment of in planta distribution of metabolic activity and gene expression of an endophytic fungus. Microbiology 143: 267-275.

Johnson, L. J., Bonth, A. C. M., Briggs, L. R., Caradus, J. R., Finch, S. C., Fleetwood, D. J., Fletcher, L. R., Hume, D. E., Johnson, R. D., Popay, A. J., Tapper, B. A., Simpson, W. R., Voisey, C. R., and Card, S. D. 2013. The exploitation of epichloae endophytes for agricultural benefit. Fungal Divers. 60:171-188.

Johnson, L. J., Johnson, R. D., Schardl, C. L., and Panaccione, D. G. 2003. Identification of differentially expressed genes in the mutualistic association of tall fescue with Neotyphodium coenophialum. Physiol. Mol. Plant Pathol. 63:305-317.

Jung, S. C., Martinez-Medina, A., Lopez-Raez, J. A., and Pozo, M. J. 2012 Mycorrhiza-induced resistance and priming of plant defenses. J. Chem. Ecol. 38:651-664.

Kovalchuk, I., Kovalchuk, O., Kalck, V., Boyko, V., Filkowski, J., Heinlein, M., and Hohn, B. 2003. Pathogen-induced systemic plant signal triggers DNA rearrangements. Nature 423:760-762.

Langmead, B., and Salzberg, S. L. 2012. Fast gapped-read alignment with Bowtie 2. Nat. Methods 9:357-359.

Ljung, K., Bhalerao, R. P., and Sandberg, G. 2001. Sites and homeostatic control of auxin biosynthesis in Arabidopsis during vegetative growth. Plant J. 28:465-474.

Malinowski, D. P., Brauer, D. K., and Belesky, D. P. 1999. The endophyte Neotyphodium coenophialum affects root morphology of tall fescue grown under phosphorus deficiency. J. Agron. Crop Sci. 183:53-60.

Martin, G. B., Bogdanove, A. J., and Sessa, G. 2003. Understanding the functions of plant disease resistance proteins. Annu. Rev. Plant Biol. 54:23-61.

McSteen, P. 2009. Hormonal regulation of branching in grasses. Plant Physiol. 149:46-55.

Metcalf, W. W., and van der Donk, W. A. 2009. Biosynthesis of phosphonic and phosphinic acid natural products. Annu. Rev. Biochem. 78:65-94.

Niklas, K. J., and Kutschera, U. 2015. Kleiber's Law: How the fire of life ignited debate, fueled theory, and neglected plants as model organisms. Plant Signal. Behav. 10:e1036216.

Pandey, S. P., and Somssich, I. E. 2009. The role of WRKY transcription factors in plant immunity. Plant Physiol. 150:1648-1655.

Peck, S. C., and van der Donk, W. A. 2013. Phosphonate biosynthesis and catabolism: A treasure trove of unusual enzymology. Curr. Opin. Chem. Biol. 17:580-588.

Plett, J. M., and Martin, F. 2012. Poplar root exudates contain compounds that induce the expression of MiSSP7 in Laccaria bicolor. Plant Signal. Behav. 7:12-15.

Plett, J. M., and Martin, F. 2015. Reconsidering mutualistic plant-fungal interactions through the lens of effector biology. Curr. Opin. Plant Biol. 26:45-50

Prestidge, R. A. P., Pottinger, R., and Barker, G. M. 1982. An association of Lolium endophyte with ryegrass resistance to Argentine stem weevil. Pages 119-122 in: 35th N.Z. Weed Pest Control.Weed Pest Control Conference. New Zealand Plant Protection Society.

Quigley, P. E. 2000. Effects of Neotyphodium lolii infection and sowing rate of perennial ryegrass (Lolium perenne) on the dynamics of ryegrass/ subterranean clover (Trifolium subterraneum) swards. Aust. J. Agric. Res. 51:47-56.

Reitz, M. U., Gifford, M. L., and Schäfer, P. 2015. Hormone activities and the cell cycle machinery in immunity-triggered growth inhibition. J. Exp. Bot. 66:2187-2197.

Saikkonen, K., Lehtonen, P., Helander, M., Koricheva, J., and Faeth, S. H. 2006. Model systems in ecology: Dissecting the endophyte-grass literature. Trends Plant Sci. 11:428-433.

Saikkonen, K., Young, C. A., Helander, M., and Schardl, C. L. 2016. Endophytic Epichlö species and their grass hosts: From evolution to applications. Plant Mol. Biol. 90:665-675.

Schardl, C. L., Grossman, R. B., Nagabhyru, P., Faulkner, J. R., and Mallik, U. P. 2007. Loline alkaloids: Currencies of mutualism. Phytochemistry 68:980-996.

Schardl, C. L., Leuchtmann, A., and Spiering, M. J. 2004. Symbioses of grasses with seedborne fungal endophytes. Annu. Rev. Plant Biol. 55: 315-340.

Schardl, C. L., Young, C. A., Hesse, U., Amyotte, S. G., Andreeva, K., Calie, P. J., Fleetwood, D. J., Haws, D. C., Moore, N., Oeser, B., Panaccione, D. G., Schweri, K. K., Voisey, C. R., Farman, M. L., Jaromczyk, J. W., Roe, B. A., O’Sullivan, D. M., Scott, B., Tudzynski, P., An, Z., Arnaoudova, E. G., Bullock, C. T., Charlton, N. D., Chen, L., Cox, M., Dinkins, R. D., Florea, S., Glenn, A. E., Gordon, A., Güldener, U., Harris, D. R., Hollin, W., Jaromczyk, J., Johnson, R. D., Khan, A. K., 
Leistner, E., Leuchtmann, A., Li, C., Liu, J., Liu, J., Liu, M., Mace, W., Machado, C., Nagabhyru, P., Pan, J., Schmid, J., Sugawara, K., Steiner, U., Takach, J. E., Tanaka, E., Webb, J. S., Wilson, E. V., Wiseman, J. L., Yoshida, R., and Zeng, Z. 2013. Plant-symbiotic fungi as chemical engineers: Multi-genome analysis of the clavicipitaceae reveals dynamics of alkaloid loci. PLoS Genet. 9:e1003323.

Scharte, J., Schön, H., and Weis, E. 2005. Photosynthesis and carbohydrate metabolism in tobacco leaves during an incompatible interaction with Phytophthora nicotianae. Plant Cell Environ. 28:1421-1435.

Schmid, J., Spiering, M. J., and Christensen, M. J. 2000. Metabolic activity, distribution and propagation of grass endophytes in planta: Investigations using the GUS reporter gene system. Pages 295-322 in: Microbial Endophytes. C. W. Bacon, J. F. White, and J. Eds (eds.). Marcel Dekker, New York.

Scott, B., Becker, Y., Becker, M., and Cartwright, G. 2012. Morphogenesis, growth, and development of the grass symbiont Epichloë festucae. Top. Curr. Genet. 22:243-264.

Simpson, W. R., Schmid, J., Singh, J., Faville, M. J., and Johnson, R. D. 2012. A morphological change in the fungal symbiont Neotyphodium lolii induces dwarfing in its host plant Lolium perenne. Fungal Biol. 116: 234-240.

Song, Y., Chen, D., Lu, K., Sun, Z., and Zeng, R. 2015. Enhanced tomato disease resistance primed by arbuscular mycorrhizal fungus. Front. Plant Sci. 6:786.

Spiering, M. J., Greer, D. H., and Schmid, J. 2006. Effects of the fungal endophyte, Neotyphodium lolii, on net photosynthesis and growth rates of perennial ryegrass (Lolium perenne) are independent of in planta endophyte concentration. Ann. Bot. (Lond.) 98:379-387.

Spiering, M. J., Lane, G. A., Christensen, M. J., and Schmid, J. 2005. Distribution of the fungal endophyte Neotyphodium lolii is not a major determinant of the distribution of fungal alkaloids in Lolium perenne plants. Phytochemistry 66:195-202.

Tan, Y. Y., Spiering, M., Christensen, M. J., Saunders, K., and Schmid, J. 1997. In planta metabolic state of Neotyphodium endophyte mycelium assessed through use of the GUS reporter gene in combination with hyphal enumeration. Pages 85-87 in: Neotyphodium/Grass Interactions. Bacon, C. W., and Hill, N. S., eds. Plenum Press, New York.

Tan, Y. Y., Spiering, M. J., Scott, V., Lane, G. A., Christensen, M. J., and Schmid, J. 2001. In planta regulation of extension of an endophytic fungus and maintenance of high metabolic rates in its mycelium in the absence of apical extension. Appl. Environ. Microbiol. 67: 5377-5383.
Tanaka, A., Cartwright, G. M., Saikia, S., Kayano, Y., Takemoto, D., Kato, M., Tsuge, T., and Scott, B. 2013. ProA, a transcriptional regulator of fungal fruiting body development, regulates leaf hyphal network development in the Epichloë festucae-Lolium perenne symbiosis. Mol. Microbiol. 90:551-568.

Tanaka, A., Takemoto, D., Hyon, G. S., Park, P., and Scott, B. 2008. NoxA activation by the small GTPase RacA is required to maintain a mutualistic symbiotic association between Epichlö̈ festucae and perennial ryegrass. Mol. Microbiol. 68:1165-1178.

Tanaka, A., Tapper, B. A., Popay, A., Parker, E. J., and Scott, B. 2005. A symbiosis expressed non-ribosomal peptide synthetase from a mutualistic fungal endophyte of perennial ryegrass confers protection to the symbiotum from insect herbivory. Mol. Microbiol. 57:1036-1050.

Tian, P., Nan, Z., Li, C., and Spangenberg, G. 2008. Effect of the endophyte Neotyphodium lolii on susceptibility and host physiological response of perennial ryegrass to fungal pathogens. Eur. J. Plant Pathol. 122:593-602.

Treutter, D. 2005. Significance of flavonoids in plant resistance and enhancement of their biosynthesis. Plant Biol. 7:581-591.

van Loon, L. C., Rep, M., and Pieterse, C. M. 2006. Significance of inducible defense-related proteins in infected plants. Annu. Rev. Phytopathol. 44:135-162.

Vázquez-de-Aldana, B. R., García-Ciudad, A., García-Criado, B., VicenteTavera, S., and Zabalgogeazcoa, I. 2013. Fungal endophyte (Epichlö̈ festucae) alters the nutrient content of Festuca rubra regardless of water availability. PLoS One 8:e84539.

Wang, L., Feng, Z., Wang, X., Wang, X., and Zhang, X. 2010. DEGseq: An $\mathrm{R}$ package for identifying differentially expressed genes from RNA-seq data. Bioinformatics 26:136-138.

Wiewióra, B., Żurek, G., and Żurek, M. 2015. Endophyte-mediated disease resistance in wild populations of perennial ryegrass (Lolium perenne). Fungal Ecol. 15:1-8.

Zhang, N., Scott, V., Al-Samarrai, T. H., Tan, Y. Y., Spiering, M. J., McMillan, L. K., Lane, G. A., Scott, D. B., Christensen, M. J., and Schmid, J. 2006 Transformation of the ryegrass endophyte Neotyphodium lolii can alter its in planta mycelial morphology. Mycol. Res. 110:601-611.

Zhang, N., Zhang, S., Borchert, S., Richardson, K., and Schmid, J. 2011. High levels of a fungal superoxide dismutase and increased concentration of a PR-10 plant protein in associations between the endophytic fungus Neotyphodium lolii and ryegrass. Mol. Plant-Microbe Interact 24:984-992.

Zhou, Y., Bradshaw, R. E., Johnson, R. D., Hume, D. E., Simpson, W. R., and Schmid, J. 2014. Detection and quantification of three distinct Neotyphodium lolii endophytes in Lolium perenne by real time PCR of secondary metabolite genes. Fungal Biol. 118:316-324. 